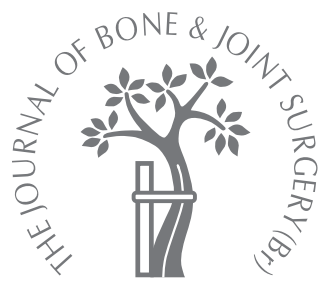

T. J. W. Matthews,

G. C. Hand,

J. L. Rees,

N. A. Athanasou,

A. J. Carr

From the Nuffield

Orthopaedic Centre,

Oxford, England

\title{
Pathology of the torn rotator cuff tendon
}

\author{
REDUCTION IN POTENTIAL FOR REPAIR AS TEAR SIZE INCREASES
}

We have studied cellular and vascular changes in different stages of full thickness tears of the rotator cuff. We examined biopsies from the supraspinatus tendon in $\mathbf{4 0}$ patients with chronic rotator cuff tears who were undergoing surgery and compared them with biopsies from four uninjured subscapularis tendons. Morphological and immunocytochemical methods using monoclonal antibodies directed against leucocytes, macrophages, mast cells, proliferative and vascular markers were used.

Histological changes indicative of repair and inflammation were most evident in small sized rotator cuff tears with increased fibroblast cellularity and intimal hyperplasia, together with increased expression of leucocyte and vascular markers. These reparative and inflammatory changes diminished as the size of the rotator cuff tear increased. Marked oedema and degeneration was seen in large and massive tears, which more often showed chondroid metaplasia and amyloid deposition. There was no association between the age of the patient and the duration of symptoms. In contrast, large and massive tears showed no increase in the number of inflammatory cells and blood vessels.

Small sized rotator cuff tears retained the greatest potential to heal, showing increased fibroblast cellularity, blood vessel proliferation and the presence of a significant inflammatory component. Tissue from large and massive tears is of such a degenerative nature that it may be a significant cause of re-rupture after surgical repair and could make healing improbable in this group.

- T. J. W. Matthews, BSc, MRCS, Research Fellow

a G. C. Hand, FRCS(Tr \& Orth), Research Fellow

I. L. Rees, MD, FRCS(Tr \&

Orth), Consultant Orthopaedic

Surgeon

N. A. Athanasou, PhD,

FRCPath, Professor of

Musculoskeletal Pathology

A. J. Carr, MCh, FRCS,

Nuffield Professor of

Orthopaedic Surgery

Nuffield Department of

Orthopaedic Surgery

Nuffield Orthopaedic Centre,

Windmill Road, Headington,

Oxford OX3 7LD, UK.

Correspondence should be sent to Mr T. J. W. Matthews; e-mail: tim.matthews@ndos.ox.ac.uk

(C)2006 British Editorial Society of Bone and Joint Surgery doi:10.1302/0301-620X.88B4. $16845 \$ 2.00$

$J$ Bone Joint Surg [Br] 2006;88-B:489-95.

Received 13 June 2005

Accepted after revision

16 December 2005

Full thickness tears of the rotator cuff are among the most frequently encountered causes of pain and dysfunction in the shoulder. ${ }^{1}$ Since shoulder complaints are the third most frequent cause (after knee and spine) of musculoskeletal symptoms in the community, rotator cuff disease represents a significant health economic issue. ${ }^{2}$ Cadaver studies in the elderly estimate the prevalence of full thickness tears to be from $5 \%$ to $30 \%{ }^{3,4}$ MRI and ultrasound studies have demonstrated that the prevalence of asymptomatic full thickness tears is from $15 \%$ to $23 \%$, 6 overall, $4 \%$ to $13 \%$ in subjects under the age of 59 years and $28 \%$ to $51 \%$ in subjects between 60 and 80 years of age.

The pathogenesis of rotator cuff tears remains unclear, but is considered to be a combination of extrinsic impingement from structures surrounding the cuff and intrinsic degeneration from changes within the tendon itself.

Recent pathological and genetic studies have emphasised the importance of intrinsic factors, ${ }^{7-11}$ but little information regarding the process of tendon degeneration is available. Kannus and Jozsa ${ }^{12}$ demonstrated characteris- tic histopathological changes in tendons that rupture spontaneously. Degenerative changes were evident in 865 of 891 cases (97\%) and included features of hypoxic degenerative tendinopathy, mucoid degeneration, tendolipomatosis and calcifying tendinopathy, either individually or in combination. They concluded that hypoperfusion is a central aspect of tendon failure. Nirschl ${ }^{13}$ also described changes in the rotator cuff tendon, such as disorganisation and fragmentation of collagen architecture and infiltration of fibroblasts and vascular tissue. Hashimoto et $\mathrm{al}^{9}$ described different patterns of degenerative change in partial and full thickness rotator cuff tears. However, they observed no correlation between the pattern of degenerative change and the size or extent of the rotator cuff tear.

Despite studies which demonstrate a critical, avascular zone within the rotator cuff, $1 \mathrm{~cm}$ proximal to its insertion, ${ }^{14-16}$ it remains unclear whether this hypoperfusion contributes to degeneration and ultimately to tendon failure. Goodmurphy et a ${ }^{17}$ demonstrated that the vascularity of the edge of a rotator cuff ten- 
Table I. Patient demographics relative to size of rotator cuff

\begin{tabular}{|c|c|c|c|c|c|}
\hline Tear size & Control & Small & Medium & Large & Massive \\
\hline Number of cases & 4 & 8 & 13 & 15 & 4 \\
\hline Mean age in yrs (range) & 20 (17 to 24$)$ & 58.8 (41 to 68$)$ & 59.9 (44 to 72$)$ & 60.8 (44 to 77 ) & $70 \quad$ (39 to 86$)$ \\
\hline Mean symptom duration in mths (range) & $\mathrm{na}^{*}$ & 17.1 (6 to 60$)$ & $34.0(6$ to 174$)$ & 41.5 (6 to 174$)$ & 43.5 (6 to 120$)$ \\
\hline Mean number of steroid injections & 0 & 1.5 & 2.2 & 1.7 & 2.0 \\
\hline
\end{tabular}

Table II. Histopathological and immunocytochemical techniques used

\begin{tabular}{lll}
\hline & Staining techniques & Target cells/tissue \\
\hline Histopathological chemical methods & Haematoxylin \& eosin & Tissue morphology \\
& $\begin{array}{l}\text { Toluidine blue } \\
\text { Congo red }\end{array}$ & $\begin{array}{l}\text { Chondroid metaplasia; mast cells } \\
\text { Amyloid }\end{array}$ \\
& CD68 & Macrophages \\
Immunocytochemical methods & CD45 & Leucocytes \\
& Mast cell tryptase & Mast cells \\
& PCNA* & Cell proliferation \\
& CD45 & Vascular endothelium \\
& D2-40 & Lymphatic endothelium
\end{tabular}

* PCNA, proliferation cell nuclear antigen

don tear was less than in tissue 2.5 to $5.0 \mathrm{~mm}$ from the edge.

This finding was contradicted by Fukuda, Hamada and Yamanaka ${ }^{18}$ who noted in partial thickness tears, that the critical zone of the tendon demonstrated relative hyperperfusion when compared with the proximal stump. Laser Doppler flowmetry studies have shown blood flow throughout the rotator cuff tendon and have demonstrated a hyperaemic response at the edge of the tear. ${ }^{19}$

The absence of clear pathological evidence as to the capability of the torn tendon to heal is reflected in variations in surgical practice. Some authors recommend excising the edge of the tear before repair while others disagree. ${ }^{10,20-22}$ It has been demonstrated that tissue less than $2.5 \mathrm{~cm}$ from the edge of the tear appears to be histologically viable in terms of microvasculature. ${ }^{17}$ These findings are supported by laser Doppler flowmetry studies. ${ }^{19}$ Additionally, the regenerative component of the tissue at the edge of the tear appears to be active with increased cellular synthesis of type-I procollagen ${ }^{17,23}$ and type-III collagen. ${ }^{24}$ Yuan et $\mathrm{al}^{25}$ suggested that a ruptured supraspinatus tendon, when compared with a control tendon, had reduced ability to heal, because of an increased degree of apoptosis and reduced production of type-I collagen. None of these previous reports investigated cell type and density relative to the size of the tear, or distance from the edge of the tear. As such, uncertainty has prevailed regarding the viability and potential for healing of rotator cuff tears which have undergone surgical repair.

We have used histochemical and immunocytochemical techniques to describe patterns of cell and tissue changes associated with inflammation and repair, in relation to the stage of the disease process and compared it with healthy rotator cuff tendon tissue.

\section{Patients and Methods}

The study group consisted of 40 specimens from 40 patients, 17 women and 23 men with a mean age of 61.8 years (39 to 86). All patients had a history of chronic rotator cuff disease with a mean duration of symptoms of 34.3 months (6 to 174) and all had failed to respond to conservative treatment. The mean number of pre-operative cortisone injections was 1.8 ( 0 to 11 ) (Table I).

In the control group, four specimens were provided by four male patients, with a mean age of 20 years (17 to 24), who had a history of recurrent dislocation of the shoulder. None of these patients had a history or evidence of rotator cuff disease.

Tissue collection and preparation. Rotator cuff tendon tissue for the patient group was obtained during open surgery for rotator cuff repair and during arthroscopic subacromial decompression. Specimens were taken from within $1.5 \mathrm{~cm}$ of the edge of the tear and throughout its whole depth and were placed immediately into formalin, before embedding in paraffin blocks. The size of the tear was recorded at the time of tissue harvest and was classified according to Post, Silver and Singh. ${ }^{26}$ The subscapularis controls were harvested during anterior stabilisation of the shoulder.

Sections were cut at $5 \mu \mathrm{m}$ using a Leica-LM microtome (Leica Microsystems, Wetzlar, Germany) and placed onto Snowcoat X-tra glass slides (Surgipath, Peterborough, United Kingdom). The paraffin was removed from the tissue sections with xylene, rehydrated in graded alcohol and selected for histochemical or immunocytochemical staining techniques (Table II).

Histological techniques. Sections were stained with haematoxylin and eosin, congo red and toluidine blue. The presence or absence of oedema and degeneration was recorded, together with the degree of fibroblast cellularity, amyloid 


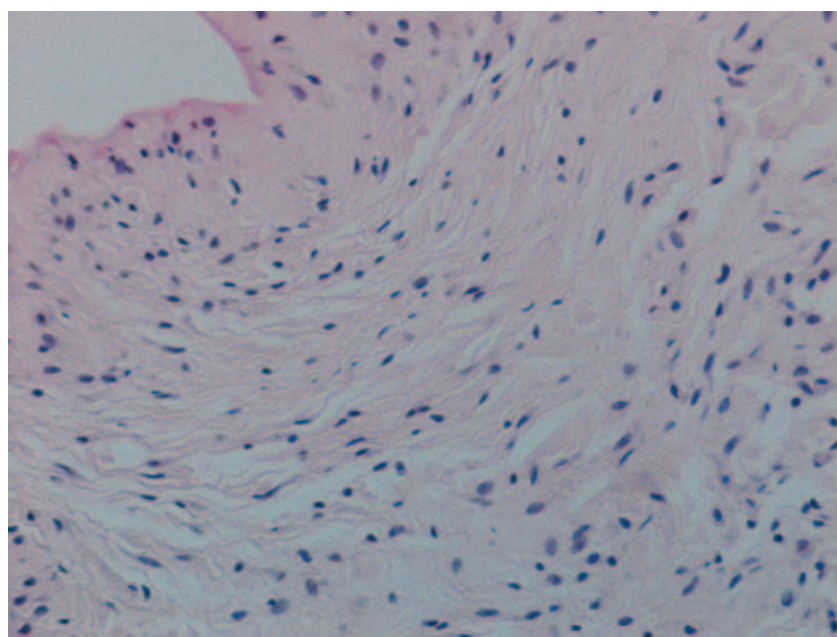

Fig. 1

Photomicrograph of the edge of a rotator cuff tendon, taken from a large tear, showing degenerative changes and oedema (haematoxylin and eosin; $\times 200)$.

deposition, chondroid metaplasia and the number of mast cells. Thickening was considered to be present when specimens demonstrated a synovial lining which was more than three cells thick.

For the immunocytochemical techniques, sections were stained with primary monoclonal antibodies directed against proliferation cell nuclear antigen, CD34 (QBEnd 10 vascular endothelial marker), CD45 (leucocyte common antigen), CD68 (macrophage-associated marker), D2-40 (lymphatic endothelial marker) and mast cell tryptase. Positive and negative control specimens were included, in addi- tion to the surgical specimens for each individual antibody staining technique.

Antibody concentrates were diluted using Dako antibody diluent, according to recommendations from the source laboratory and Chemate EnVision kit (Dako UK Ltd., Ely, United Kingdom). This employs an indirect immunoperoxidase technique to visualise the antibodies. Sections were then counterstained in haematoxylin and 'blued' in sodium hydrogen carbonate. All sections were then dehydrated through graded alcohol and xylene, coverslipped using DPX mounting agent and examined under light microscopy at 100, 200 and 400 times magnification, using an Olympus LN-40 microscope (Olympus UK Ltd., Southall, United Kingdom).

In addition to the morphological observations, leucocyte, macrophage, mast cell and blood vessel numbers were counted in ten random high-powered (x400 magnification) fields of view in each specimen.

The blood vessel counts for the different sized rotator cuff tears were compared using the Kruskall-Wallis test with $\mathrm{p} \leq 0.5$ considered as significant.

\section{Results}

Changes in the synovial intima, subintima and capsule. All specimens in the study group showed oedema within the extracellular matrix and degenerative changes with fragmentation and disorientation of collagen fibrils (Fig. 1). In 11 of the $40(28 \%)$ specimens the synovial lining was more than three cells in thickness (Fig. 2a) with the remaining specimens being of normal thickness (Fig. 2b). Thickening of the synovial lining was noted in four of the $13(31 \%)$ medium sized tears and four of the eight $(50 \%)$ small tears. None of the massive tears and three of the 15

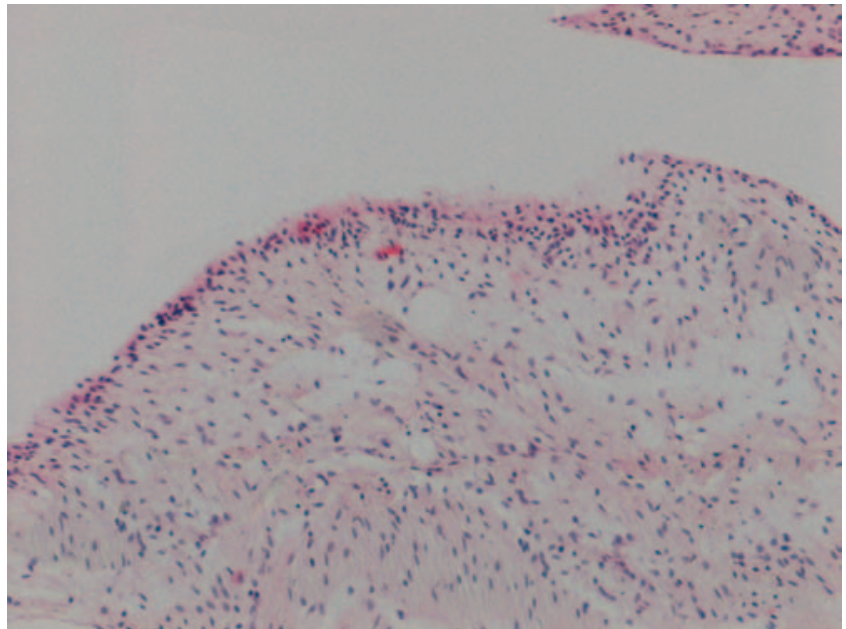

Fig. 2a

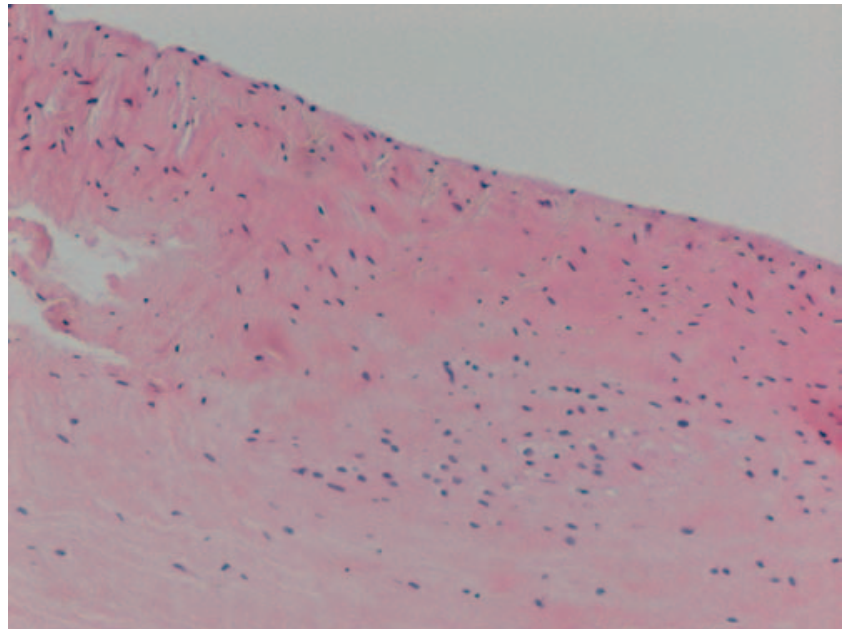

Fig. $2 b$

Figure 2a - Photomicrograph of the edge of a rotator cuff tendon taken from a small tear and showing a thickened synovial lining (haematoxylin and eosin; $\times 100$ ), Figure $2 b$ - Photomicrograph of the edge of a rotator cuff tendon, taken from a large tear, showing a normal synovial lining (haematoxylin and eosin; $\times 100$ ). 


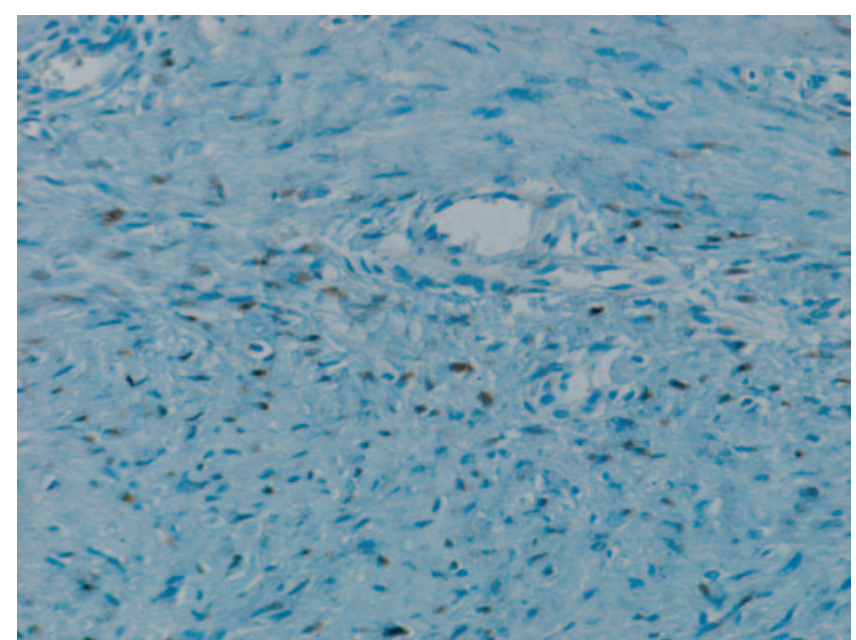

Fig. 3

Photomicrograph of rotator cuff tendon, taken from a small tear, showing positive staining (dark brown) for proliferating fibroblasts (proliferation cell nuclear antigen; $\times 100)$.

$(20 \%)$ large tears, had a thickened lining. There was no difference in the mean duration of symptoms in those patients with a thickened or normal synovial lining and none of the control specimens showed a thickening of the synovial lining.

In the subintima, 20 of the $40(50 \%)$ specimens showed reduced fibroblast cellularity, $14(35 \%)$ had normal cellularity and six $(15 \%)$ had increased cellularity, in relation to the control specimens. All specimens which showed increased cellularity also showed positive staining for proliferation cell nuclear analysis in proliferating cells (Fig. 3). As the tear size increased there was a trend towards decreasing fibroblast cellularity and an absence of proliferation cell nuclear analysis expression (Table III).

The extracellular matrix. Fibrocartilaginous metaplasia was identified morphologically and by toluidine blue staining in 29 of the $40(73 \%)$ specimens. Chondroid metaplasia was

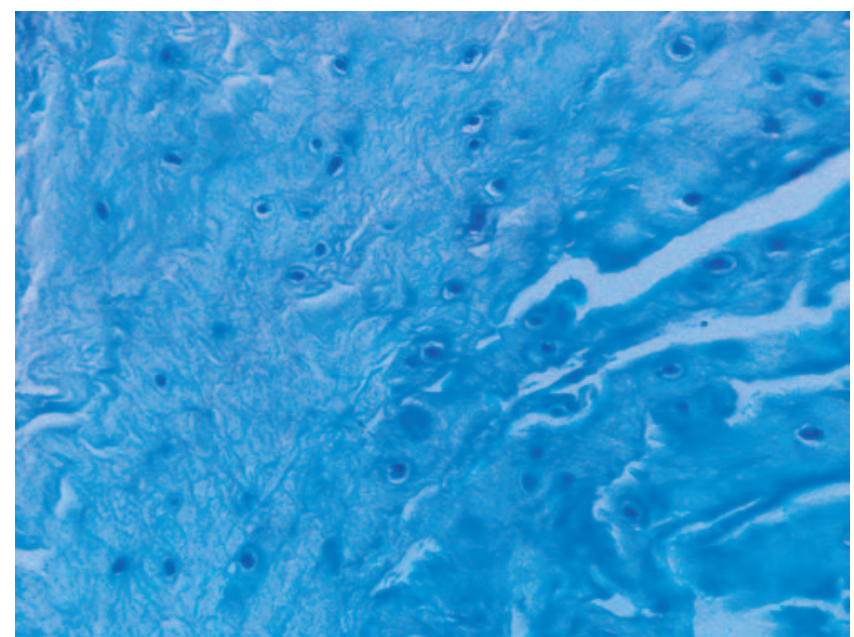

Fig. 4

Photomicrograph of rotator cuff tendon, from a massive tear, showing widespread chondroid metaplasia (toluidine blue; $\times 200$ ).

observed mainly in areas of low cellularity. Specimens from medium, large and massive tears (Fig. 4) had significantly more evidence of chondroid metaplasia than those from small tears. There was no discernible difference in the degree of vascularity in those specimens, with or without evidence of chondroid metaplasia. There was also no significant difference in the mean duration of symptoms of those patients with histological evidence of chondroid metaplasia and those without. None of the control specimens showed evidence of chondroid metaplasia.

Of the 40 specimens $14(35 \%)$ had positive staining for amyloid, which was more commonly seen in cases with large and massive tears. The mean age of the patient and the duration of symptoms was not related to the presence or extent of amyloid deposition, which was seen over a wide age range (39 to 77 years). None of the control specimens showed evidence of amyloid deposition.

Table III. Histopathological features observed related to size of rotator cuff

\begin{tabular}{|c|c|c|c|c|c|}
\hline Feature & $\begin{array}{l}\text { Control } \\
(n=4)\end{array}$ & $\begin{array}{l}\text { Small } \\
(n=8)\end{array}$ & $\begin{array}{l}\text { Medium } \\
(n=13)\end{array}$ & $\begin{array}{l}\text { Large } \\
(n=15)\end{array}$ & $\begin{array}{l}\text { Massive } \\
(n=4)\end{array}$ \\
\hline Fibroblast cellularity & Normal & Enhanced & Normal & Normal & Reduced \\
\hline Cell proliferation & $\begin{array}{l}\text { Weak } \\
\text { staining }\end{array}$ & $\begin{array}{l}\text { Strongly } \\
\text { positive staining }\end{array}$ & $\begin{array}{l}\text { Positive } \\
\text { staining }\end{array}$ & $\begin{array}{l}\text { Weak } \\
\text { staining }\end{array}$ & $\begin{array}{l}\text { No } \\
\text { staining }\end{array}$ \\
\hline Thickened synovial lining (\% specimens) & 0 & 50 & 31 & 20 & 0 \\
\hline Positive staining for amyloid (\% specimens) & 0 & 25 & 30 & 40 & 25 \\
\hline Chondroid metaplasia (\% specimens) & 0 & 37 & 76 & 80 & 75 \\
\hline \multicolumn{6}{|l|}{ Inflammatory cell count ${ }^{*}$} \\
\hline Macrophages & 2 & 19 & 9 & 3 & 4 \\
\hline Mast cells & 0 & 10 & 7 & 5 & 5 \\
\hline Leucocytes & 3 & 9 & 6 & 2 & 0 \\
\hline Mean vessel count ${ }^{\dagger}$ & 4.5 & 32.2 & 18.4 & 6.1 & 0.5 \\
\hline
\end{tabular}

* mean number of cells in ten high-power fields of view (magnification $x$ 400)

$\dagger$ mean number of vessels in ten high-power fields of view (magnification $x$ 400) 


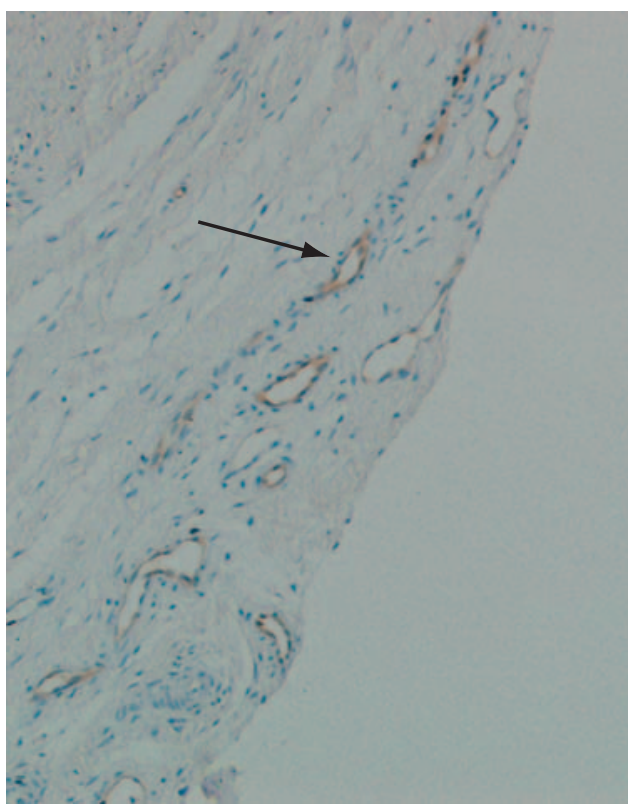

Fig. $5 a$

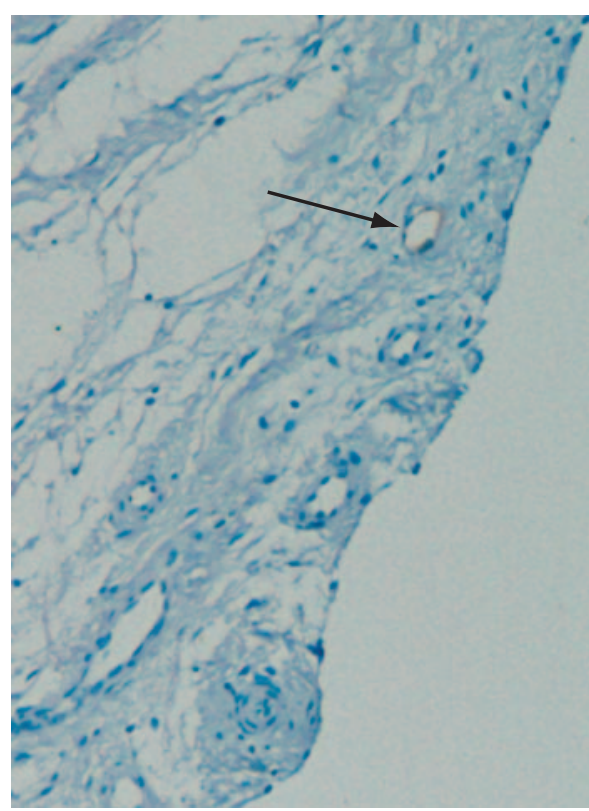

Fig. 5b

Photomicrograph of the edge of a rotator cuff tendon, taken from medium-sized tear a) showing positive staining for vascular endothelium (CD34 QBend 10 vascular endothelial marker; $x 200$ ), b) showing positive staining for lymphatic endothelium only (D2-40; x200). The same lymphatic vessel, indicated by the arrow, is seen to stain positively for both antibodies, with blood vessels only staining for CD34.

Vascular changes. CD34-positive vessels were abundant in specimens showing increased fibroblast cellularity. In three specimens with reduced fibroblast cellularity and a high degree of degenerative change in the matrix, considerably fewer CD34-positive vessels were present. As the tear size increased, there was a trend towards decreasing vascularity. The mean vessel count was 32.2 for small tears, 18.4 for medium, 6.1 for large, 0.5 for massive and 4.5 for control specimens. There was a significant difference between all the groups ( $p=0.008$ ) when the Kruskal-Wallis rank test was applied to these data (Table III).

Lymphatic vascular channels were demonstrated in small- and medium-sized tears only and these were most often found in areas of high fibroblast cellularity (Fig. 5). No lymphatic vessels were seen in control specimens.

Inflammatory cell changes. The majority of leucocytes were scattered throughout the subintimal layer and the largest number were seen in those specimens showing reparative changes with increased fibroblast cellularity. There were fewer leucocytes present in those specimens which contained mature fibrous tissue with low fibroblast cellularity. Most of the macrophages were found in the subintimal layers although some were also present in the synovial lining in those specimens which had a thickened synovium. Macrophages were numerous in specimens showing increased fibroblast cellularity and the extent of the macrophage infiltrate was generally less in those with less fibroblast cellularity.

Mast cells were found in 19 of $38(50 \%)$ specimens stained with toluidine blue. The majority were isolated cells, located around blood vessels, with the remainder in the synovial lining and scattered throughout the tissue. Most mast cells were seen in specimens with increased fibroblast cellularity and were seen to decrease in number as the fibroblast cellularity of the specimen decreased.

Small numbers of mast cells and positively staining cells for leucocyte common antigen and CD68 were noted in the control specimens. These cells were mainly located around blood vessels. As the size of the rotator cuff tear increased, the numbers of mast cells, and CD68 and CD45 positively staining cells, decreased (Table III). The numbers of CD68positive cells and mast cells did not continue to decrease from large to massive tears, whereas the number of CD45 positively staining cells did decrease (Table III). The number of mast cells, CD68 and CD45 positively staining cells was similar to those seen in the larger tears.

\section{Discussion}

Reparative response. The normal healing processes of connective tissues rely on the proliferation of new blood vessels and fibroblasts to form granulation tissue. The fibroblasts migrate into the wound and undergo a period of intense mitotic activity. The role of these fibroblasts is chiefly to secrete extracellular matrix proteins, in particular type-I and type-III collagen and glycosaminoglycans. ${ }^{27}$ Newlyproduced granulation tissue slowly develops into mature scar tissue as the wound heals.

We have found that the fibroblast population decreases as the size of the tear in the rotator cuff increases. The 
larger fibroblast population seen in the smaller tears is also actively proliferating and is part of an active reparative process. In contrast, fewer fibroblasts are present in the larger sized tears, with no evidence of cell proliferation and there is evidence of a diminished reparative response to healing.

It was also observed that some of the smaller tears had a thickened synovial lining which was not noted in the larger tears. The presence of a thickened and inflamed synovial lining indicates an attempt at repair and is regularly seen in conditions such as osteoarthritis and rheumatoid arthritis. There was a significant decrease in blood vessel number as tear size increased, with the smallest number being seen in massive tears. These findings indicate a significantly greater reparative process present in smaller tears when compared with larger tears.

Inflammatory response. The mean duration of symptoms in this study was 34.3 months (6 to 174), it is therefore not surprising that the specimens examined mainly showed changes of chronic inflammation and repair. The processes of resolution, regeneration and repair are sequential in acute inflammation, but occur simultaneously in chronic inflammation. ${ }^{27}$ Chronic inflammation is typified by the presence of phagocytic cells such as macrophages and organisation as evidenced by new vessel formation, fibroblasts and collagen deposition, together with other inflammatory cells such as lymphocytes and mast cells. We found evidence of this chronic inflammatory state to the greatest degree in the smaller tears within the rotator cuff tendon.

Macrophages were seen to decrease significantly in number from small to medium tears and from medium to large and massive tears. This trend was also noted for mast cells and leucocyte numbers. Interestingly, the numbers of mast cells and macrophages appeared to reach a baseline number, as no further decrease was noted when comparing large with massive tears. It is reasonable to consider that this number of inflammatory cells may represent a 'normal' number in such tissue, as similar numbers of these cells were seen in control specimens. In addition to the decrease in the macrophage, mast cell and leucocyte cell counts as the tear size increased, there were also significant decreases in the number of fibroblasts and blood vessels.

These observations indicate that the inflammatory process diminishes as the tear size increases and the potential for the tendon tear to heal by means of resolution, regeneration and repair diminishes as the tear size increases.

Previous histological studies in rotator cuff tendons, as well as in other tendons, have indicated that there is no significant evidence of an inflammatory component following tendon rupture. However, Cetti, Junge and Vyberg ${ }^{28}$ found histological evidence of inflammation in Achilles tendons using immunocytochemical methods. Our study used similar methods to identify inflammatory cells. It may be that in earlier studies of both ruptured rotator cuff and Achilles tendon specimens, inflammatory cells were present but had simply not been identified.
Intrinsic changes within the tendon. Increased numbers of chondrocytes have been observed in the proximal stump of bursal-side, partial thickness rotator cuff tears, in areas of relative avascularity and diminished numbers of fibroblasts. ${ }^{18}$ Other tendinopathies have been shown to demonstrate swelling and rounding of tenocytes, thought to be evidence of early chondroid metaplasia. ${ }^{29}$ We noted that chondroid metaplasia was evident in areas of low fibroblast cellularity and that these specimens were from the larger tears. Additionally, we found no association between the presence of chondroid metaplasia and either chronicity of the symptoms or the age of the patient.

Amyloid deposition also appeared to be more prevalent in the larger sized tears and again was not associated with the chronicity of the symptoms, or the age of the patient.

Confounding factors. The prevalence and extent of full thickness rotator cuff tears is known to increase with age..$^{3-6}$ We have shown significant cellular changes as tear size increases. These changes appear to be independent of the age of the patient. However, the mean age of the patients with massive tears was significantly greater and this may have contributed to the increased degree of degenerative change seen. These findings suggest that there are other factors in addition to age causing tendon degeneration. This supports evidence from Harvie et $\mathrm{al}^{7}$ that rotator cuff tears have a significant genetic component in their aetiology.

There were significant differences seen in the mean duration of symptoms for small, medium and large tears, but this was not the case when comparing large and massive tears. The longer duration of symptoms in larger tears could account for the increased degree of degeneration.

There is some clinical and histological evidence to suggest that more than three or four subacromial steroid injections have a damaging effect on the rotator cuff tendon. ${ }^{30,31}$ The largest number of injections in this study was given to the medium-sized tear group. We found no evidence to suggest that the larger tears had received a greater number of injections; some large tears had received none.

Implications for surgical practice. Our study shows that the tissue with the greatest potential for successful healing is found in the smaller tears. This tissue has both the cellular and vascular components required for successful healing, in contrast with large and massive tears which appear to have lost their ability to heal and demonstrate a transition into a highly degenerate, inert tissue. These histopathological findings may help to explain the high rate of re-rupture seen in clinical and radiological studies. ${ }^{32-37}$ The expectation of a long-lasting repair in larger tears may be misplaced. However, re-attachment of the tendon edge to the greater tuberosity may permit vascular ingrowth and increase, to some extent, the potential for healing. Techniques of tendon repair which maximise contact with bone and promote vascular ingrowth have a clear theoretical advantage. Symptomatic smaller tears which may over time extend to larger tears, should probably be repaired as early as possible, while they still have the ability to heal. 
The use of subacromial cortisone injections to reduce pain remains the mainstay for non-operative treatment. While some evidence suggests a limit of three to four injections before a detrimental effect occurs, ${ }^{30,31,34}$ we did not find any association between the number of cortisone injections given and the size of the tear. This may support the continued use of cortisone injections in the non-operative management of patients with full thickness rotator cuff tears and help avoid surgery. It is accepted that glucocorticoid suppresses inflammation by reducing macrophage activity and reducing angiogenesis, both of which are integral to the inflammatory process. ${ }^{38}$

We know from this study that the smaller full thickness tears show the greatest potential to heal. Therefore we question whether the use of subacromial cortisone injections in patients with small full thickness tears may reduce their ability to heal and subsequently drive the tissue into a more degenerative, inert state. Uncertainty also surrounds the role of external mechanical forces (impingement) in the onset and progression of the degenerative change shown in this study. These latter two considerations require further study.

Full thickness rotator cuff tendon tears demonstrate evidence of degeneration and oedema which becomes more pronounced as the tear size increases. There is also a significant inflammatory component in smaller tears when compared with larger ones and therefore, these smaller tears show a greater potential to heal.

Our findings have ramifications for patient selection for an anticipated successful surgical repair of the rotator cuff and raise questions about the use of cortisone injections and subacromial decompression.

No benefits in any form have been received or will be received from a commer cial party related directly or indirectly to the subject of this article.

\section{References}

1. Bunker T. Rotator cuff disease. Curr Orthop 2002;16:223-33.

2. Urwin M, Symmons D, Allison T, et al. Estimating the burden of musculoskeletal disorders in the community: the comparative prevalence of symptoms at different anatomical sites, and the relation to social deprivation. Ann Rheum Dis 1998;57: 649-55.

3. Lehman C, Cuomo F, Kummer FJ, Zuckerman JD. The incidence of full thickness rotator cuff tears in a large cadaveric population. Bull Hosp Jt Dis 1995;54:30-1.

4. Neer CS 2nd, Satterlee CC, Dalsey RM, Flatow EL. The anatomy and potential effects of contracture of the coracohumeral ligament. Clin Orthop 1992;280:182-5

5. Tempelhof S, Rupp S, Seil R. Age-related prevalence of rotator cuff tears in asymptomatic shoulders. J Shoulder Elbow Surg 1999;8:296-9

6. Sher JS, Uribe JW, Posada A, Murphy BJ, Zlatkin MB. Abnormal findings on magnetic resonance images of asymptomatic shoulders. J Bone Joint Surg [Am] 1995;77-A:10-15

7. Harvie P, Ostlere SJ, Teh J, et al. Genetic influences in the aetiology of tears of the rotator cuff: sibling risk of a full-thickness tear. J Bone Joint Surg [Br] 2004;86-B: 696-700.

8. Ozaki J, Fujimoto S, Nakagawa Y, Masuhara K, Tamai S. Tears of the rotator cuff of the shoulder associated with pathological changes in the acromion: a study in cadavera. J Bone Joint Surg [Am] 1988;70-A:1224-30.

9. Hashimoto T, Nobuhara K, Hamada T. Pathologic evidence of degeneration as a primary cause of rotator cuff tear. Clin Orthop 2003:415:111-20.
10. Codman EA. The Shoulder: rupture of the supraspinatus tendon and other lesions in or about the subacromial bursa. Boston: Thomas Todd, 1934.

11. Uhthoff HK, Sano H. Pathology of failure of the rotator cuff tendon. Orthop Clin North Am 1997;28:31-41

12. Kannus $\mathbf{P}$, Jozsa $\mathbf{L}$. Histopathological changes preceding spontaneous rupture of a tendon: a controlled study of 891 patients. J Bone Joint Surg [Am] 1991:73-A 1507-25.

13. NirschI RP. Rotator cuff tendinitis: basic concepts of pathoetiology. Instr Course Lect 1989;38:439-45

14. Lindblom K. On pathogenesis of rupture of the tendon aponeurosis of the shoulder joint. Acta Radiol 1939;20:563.

15. Moseley HF, Goldie I. The arterial pattern of the rotator cuff of the shoulder. J Bone Joint Surg [Br] 1963;45-B:780-9

16. Lohr JF, Uhthoff HK. The microvascular pattern of the supraspinatus tendon. Clin Orthop 1990;254:35-8.

17. Goodmurphy CW, Osborn J, Akesson EJ, et al. An immunocytochemical analysis of torn rotator cuff tendon taken at the time of repair. J Shoulder Elbow Surg 2003;12: 368-74.

18. Fukuda H, Hamada K, Yamanaka K. Pathology and pathogenesis of bursal-side rotator cuff tears viewed from en block histologic sections. Clin Orthop 1990:254: 75-80.

19. Swiontkowski MF, lannotti JP, Boulas HJ, Esterhai JL. Intraoperative assessment of rotator cuff vascularity using laser Doppler flowmetry. In: Post M, Morrey BF, Hawkins RJ, eds. Surgery of the shoulder. St. Louis: Mosby-Year Book, 1990.

20. Uhthoff HK, Sarkar K. Surgical repair of rotator cuff ruptures: the importance of the subacromial bursa. J Bone Joint Surg [Br] 1991;73-B:399-401.

21. DePalma AF. Disorders associated with biological ageing of the shoulder. In: Surgery of the shoulder. Third ed. Philadelphia: J.B. Lippincott, 1983:242-98.

22. McLaughlin HL. Rupture of the rotator cuff. J Bone Joint Surg [Am] 1962;44-A 979-83.

23. Hamada K, Okawara Y, Fryer JN, Tomonaga A, Fukuda H. Localization of mRNA of procollagen alpha 1 type I in torn supraspinatus tendons: in situ hybridisation using digoxigenin labeled oligonucleotide probe. Clin Orthop 1994;304:18-21.

24. Kumagai J, Uhthoff K, Sarkar K, Murnaghan JP. Collagen type III in rotator cuff tears: an immunohistochemical study. J Shoulder Elbow Surg 1992:187-92.

25. Yuan J, Murrell GA, Wei AO, Wang MX. Apoptosis in rotator cuff tendonopathy. J Orthop Res 2002;20:1372-9

26. Post M, Silver R, Singh M. Rotator cuff tear: diagnosis and treatment. Clin Orthop 1983;173:78-91

27. McGee J O'D, Isaacson PG, Wright NA. Oxford textbook of pathology. Oxford Oxford University Press, 1992

28. Cetti R, Junge J, Vyberg $\mathbf{M}$. Spontaneous rupture of the Achilles tendon is preceded by widespread and bilateral tendon damage and ipsilateral inflammation: a clinical and histopathologic study of 60 patients. Acta Orthop Scand 2003;74:78-84.

29. Khan KM, Cook JL, Bonar F, Harcourt P, Astrom M. Histopathology of common tendinopathies: update and implications for clinical management. Sports Med 1999; 27:393-408.

30. Bjorkenheim JM, Paavolainen P, Ahovuo J, Slatis P. Surgical repair of the rotator cuff and surrounding tissues: factors influencing the results. Clin Orthop 1988;236: $148-53$

31. Watson M. Major ruptures of the rotator cuff: the results of surgical repair in 89 patients. J Bone Joint Surg [Br] 1985;67-B:618-24.

32. Harryman DT 2nd, Mack LA, Wang KY, et al. Repairs of the rotator cuff: correlation of functional results with integrity of the cuff. J Bone Joint Surg [Am]1991;73-A 982-9.

33. Galatz LM, Ball CM, Teefey SA, Middleton WD, Yamaguchi K. The outcome and repair integrity of completely arthroscopically repaired large and massive rotator cuff tears. J Bone Joint Surg [Am] 2004;86-A:219-24.

34. Ma HL, Wu JJ, Lin CF, Lo WH. Surgical treatment of full thickness rotator cuff tear in patients younger than 40 years. Zhonghua Yi Xue Za Zhi (Taipei) 2000;63:452-8.

35. von Engelhardt LV, von Falkenhausen M, Fahmy U, et al. MRI after reconstruction of the supraspinatus tendon: MR-tomographic findings. Z Orthop Ihre Grenzgeb 2004;142:586-91 (in German).

36. Klepps S, Bishop J, Lin J, et al. Prospective evaluation of the effect of rotator cuff integrity on the outcome of open rotator cuff repairs. Am J Sports Med 2004;32:1716-22.

37. Gerber C, Fuchs B, Hodler J. The results of repair of massive tears of the rotator cuff. J Bone Joint Surg [Am]2000;82-A:505-15.

38. Rhen T, Cidlowski JA. Antiinflammatory action of glucocorticoids: new mechanisms for old drugs. New Engl J Med 2005:353:1711-23. 